\title{
Effects of land use/land cover and climatic change on the ecosystem of North Ningxia, China
}

\author{
Hazem T. Abd El-Hamid ${ }^{1,2}$ • Wei Caiyong ${ }^{2}$ - Mohammed A. Hafiz ${ }^{3}$ • Elhadi K. Mustafa ${ }^{4}$
}

Received: 25 March 2020 / Accepted: 18 September 2020 / Published online: 16 October 2020

(C) The Author(s) 2020

\begin{abstract}
Land use/land cover change (LUCC) and climate changes are responsible for degradation of any ecosystem in arid and semi-arid regions. Studying the ecological variations is particularly essential for any type of sustainable development, in which LUCC considers as one of the chief inputs. The main objective is to evaluate the impacts of LUCC and climatic changes on the Ecosystem Vulnerability $\left(\mathrm{E}_{\mathrm{S}} \mathrm{V}\right)$ using remote sensing and some statistical models around the Yellow River, Ningxia, China. Eleven classes of LUCC were identified during 1995 and 2019: village land, bare land, grassland, industrial land, irrigated land, swamp land, tidal flat, transportation land, urban land, water bodies, and water channels. Grassland may be decreased annually with percentage $-5.873 \%$ due to some human activities and environmental changes in climate from one season to another. About $24.23 \mathrm{~km}^{2}$ and $24.86 \mathrm{~km}^{2}$ was converted from grassland to industrial lands and irrigated lands, respectively. $\mathrm{E}_{\mathrm{S}} \mathrm{V}$ has been calculated using LULC, DEM, slope, soil, and geology. About $45 \%$ and $60 \%$ of 1995 and 2019 , respectively, undergone moderate vulnerability. The annual rate of $E_{S} \mathrm{VI}$ decreased in low and reasonable but it was increased in moderate, high, and extreme showing $-4.166 \%$ as a total percentage of annual vulnerability. High vulnerability area needs proper management. Majority of vegetation area is located in zone under the moderate vulnerability zone; in contrast, grasslands were subjected to high vulnerability. Areas around the Yellow River were subjected to drought and flooding due to climatic change affecting negatively on the production of crops. Also, the desert lands of the study area have been turned to agriculture according to statistical model. Population growth, industrial development, and governmental policies for ecosystem protection were responsible for major changes. This study is more beneficial for decision-making in eco-environmental protecting and planning. Results of this study could help planners in formulating effective strategies for better management of ecosystem.
\end{abstract}

Keywords Yellow River $\cdot$ Dynamics $\cdot$ LULC $\cdot$ Vulnerability $\cdot$ Remote sensing

\section{Introduction}

Responsible Editor: Amjad Kallel

Hazem T. Abd El-Hamid

hazem_ecology@yahoo.com

1 National Institute of Oceanography and Fisheries, NIOF, Alexandria, Egypt

2 Ningxia Institute of Remote Sensing Survey \& Mapping, Yinchuan 750021, China

3 Faculty of Science and Arts, Department of Mathematics, Najran University, Najran, Saudi Arabia

4 Faculty of Geosciences and Environmental Engineering, Department of Surveying and Geo-Informatics, Southwest Jiaotong University, Chengdu 610031, Sichuan, China
Fundamental changes of any environment may be attributed to natural or anthropogenic activities. Due to the change in global climate, the land surface temperature (LST) has increased, which has affected land use/land cover change (LUCC), vegetated areas, water resources, etc. Choudhury et al. (2019) stated that changes in climatic changes are responsible for various environmental problems. LST refers to the temperature of the earth surface including the temperature of bare soil, the canopy of vegetation, etc. Climate change has had an important effect on water resources in Africa principally on the west coast where the demand for water is high for agriculture. Rivers, lakes, and wetlands which are the principal surface water resources of the region suffered devastating consequences by the drought of the early $1970 \mathrm{~s}$ 
(Kandissounon et al. 2018). This may cause adverse impacts on socio-economic, biological, climatic, and hydrological aspects of the environment. Recently, with more development protocols of the Chinese government focused on Northwest China, North Ningxia becomes one of the most important provinces in China especially in the field of agriculture and industry.

Population growth, migration, and urbanization lead to negative change on the Yellow River community. Vaidya et al. (2018) stated that people altered the harvesting patterned and its varieties from traditional to market valuable crops. Land use and land cover change is a very important issue considering in many parts of the globe. Cities near the Yellow River have been populated by humans who were interested with farming activities. Poor communities of developing country as Ningxia are hardest hit by the impacts of climate change (Rahman et al. 2016).

Nowadays, utilization and exploitation of energy have negatively affected the ecosystem balance; therefore, the ecosystem in North Ningxia is more sensitive to change and stress (Li and Liu 2008). For effective assessment of ecosystem vulnerability $\left(\mathrm{E}_{\mathrm{S}} \mathrm{V}\right)$, firstly, vulnerability concepts have been altered according the scope of the study. Susceptibility of ecosystem is a function of contact, sensitivity, and adaptive capability. Exposure components characterize the stressors and the entities under stress, sensitivity mechanisms illustrate the first-order effects of the pressures, and adaptive capability constituents describe replies to the properties of the stresses (Saaty and Vargas 1991). A variety of models have been developed to assess the vulnerability: Integrated Assessment Act (IAA), analytical hierarchy process (APH), and forecast weighing method (IWM) (Li et al. 2009). This present study selected a spatial model to evaluate the ecosystem vulnerability $\left(E_{S} V\right)$ of the area around the Yellow River, North Ningxia.

Recently, remote sensing and geographic information system (GIS) have been integrated as a strong technology to assess LUCC and $\mathrm{E}_{\mathrm{S}} \mathrm{V}$. Remote sensing techniques have been successful in mapping and detecting land use/cover changes. The spatial and temporal distribution of land use/cover using satellite images is critically significant to identify and explain the phenomenon of global environmental change (Ozesmi and Bauer 2002). Depending on remote sensing images, spatial interpolation was applied for resolving many problems of prediction. One of the difficulties facing ecological changes is the truth of area exactly calculating the actual data (Azpurua and Ramos 2010). So, spatial interpolation models can be welldefined as a series of statistical methods used to predict the values of phenomena in sites where accurate measurements are little.

The innovation of the present study is represented by simulation and extracting the sensitivity area to flood and drought based on LUCC and climatic change. Therefore, the objectives of this study are to (1) assess the ecosystem sensitivity affected by LUCC and climate changes using statistical simulation and data of remote sensing technology; (2) to study the LUCC from 1995 to 2019 using satellite data, assess the transition of LULC and land use dynamics, establish an Ecosystem Vulnerability Index ( $\left.\mathrm{E}_{\mathrm{S}} \mathrm{VI}\right)$ based on some ecological variables; and finally, (3) to establish a statistical model for assessing the changes in water, vegetation, and drought as an indicator of climatic change.

\section{Materials and methods}

\section{Study area}

North Ningxia is located at longitude $105^{\circ} 45^{-} \mathrm{E}$ to $107^{\circ} 00^{-} \mathrm{E}$ and latitude $38^{\circ} 20^{-} \mathrm{N}$ to $39^{\circ} 30^{-} \mathrm{N}$ (Fig. 1). The Yellow River Irrigated District is the greatest significant residence of agricultural production in Ningxia with an arid and semi-arid climate. It is composed of the alluvial plans along the Yellow River and the diluvia piedmont of Helan. The Yellow River irrigation is one of the large irrigation areas with advantageous flow irrigation conditions, and also a major production base of commodity grain in Northwest China. In 1984, Ningxia is the first to achieve self-sufficiency of food in the northwest region. Around the Yellow River, the crops mainly are including wheat, rice, potato, and minor cereals accounting more than $80 \%$ of the planting area of farm crops.

\section{Remote sensing analysis}

\section{Data collection and image preprocessing}

Landsat images were acquired from http://glovis.usgs.gov. The study area was located in one scene: path 129, raw 34. Landsat Thematic Mapper (TM) and Enhanced Thematic Mapper (ETM and Operational Land Imager (OLI) images were acquired in 1995, 2000, 2005, 2010, 2015, and 2019, respectively. Atmospheric correction method is used to correct primarily the wavelengths of visible near infrared and shortwave infrared information (Abd El-Hamid et al. 2019). The geographical coordinates are unified by the latitude and longitude coordinate system Xian_1980_GK_CM_105 E, and the projection mode is the horizontal axis Mercator projection. Finally, the study area was selected by image subset for further analysis. A flowchart was presented showing details of the methodology (Fig. 2).

\section{Classification of LUCC}

Firstly, unsupervised classification was primarily applied to categorize the classes based on their spectral properties. The land use/cover was classified using supervised classification based on the land cover classification system and field 
Fig. 1 Map showing the location of the study area

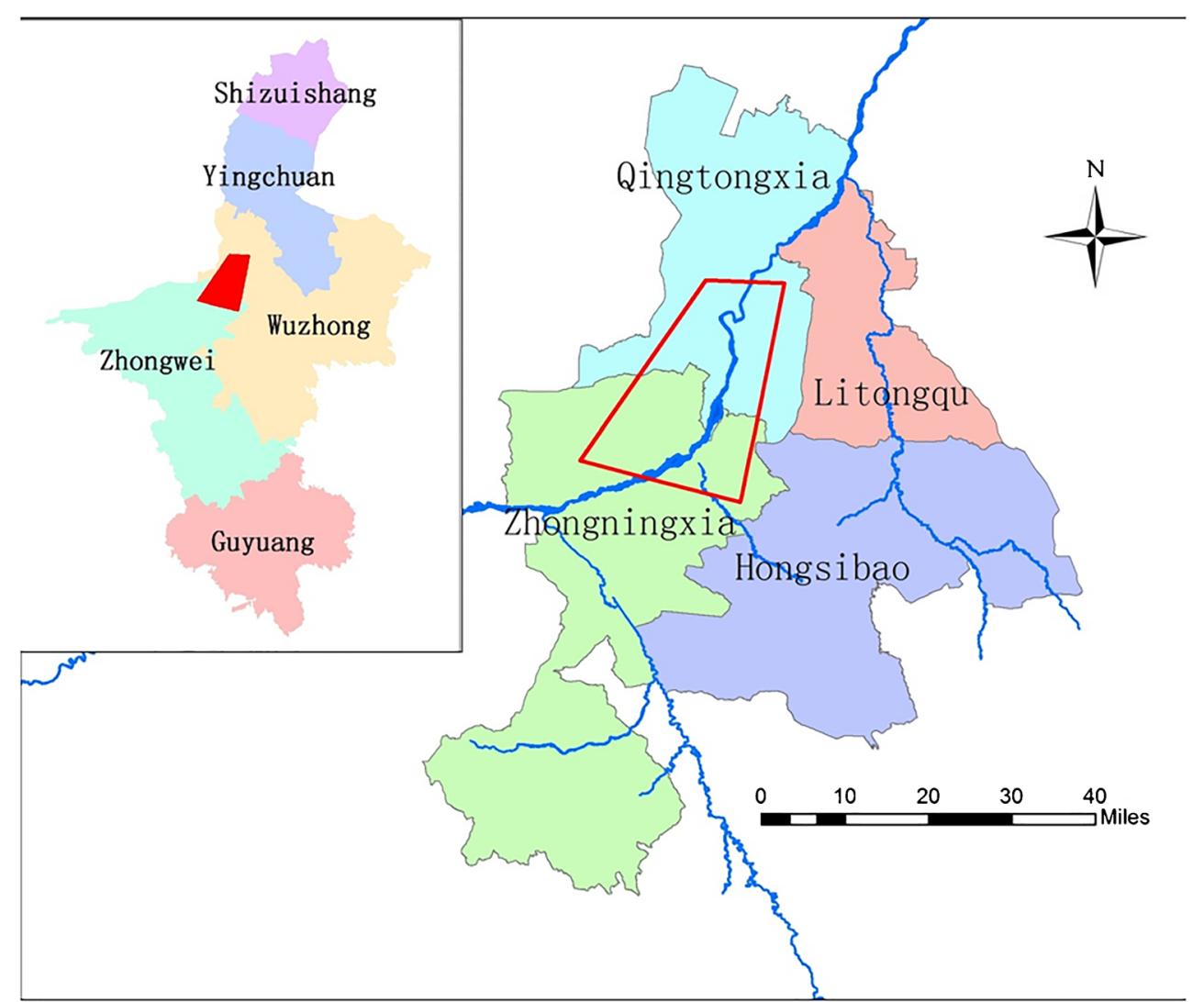

observation as ground truth. Finally, the derived classes were mapped and analyzed using ArcGIS 10.5 software to measure the alteration of land uses and regulate the quantity, position, and degree of gain or loss for each specific class.

\section{LULC transition}

Conversion matrix was used to differentiate the changes of each class at the expense of others and its general structure. Entries on the diagonal (that is, $\mathrm{P}_{\mathrm{jj}}$ ) indicate the amount of land use/cover category which remained persistence of class $j$ between the time period and used to calculate the gains and the losses of land use/cover classes whereas the off-diagonal entries show the size of the area that transitioned from category " $i$ " to a different category " $j$ " during the time interval (Aldwaik and Pontius 2012). For ease of reference, the equations and notation used to compute various components are presented as follows: the land use data is mapped and evaluated using two remote sensing images in 1995 and 2019.

$$
\begin{gathered}
\left(\begin{array}{ccc}
p_{11} & \cdots & p_{1 n} \\
\vdots & \ddots & \vdots \\
p_{n 1} & \cdots & p_{n n}
\end{array}\right) \\
0 \leq p_{11<1} \\
\left.\sum_{i=1}^{n} p_{i j} x=1, i, j=1,2, \ldots \ldots, n\right)
\end{gathered}
$$

where $P_{i j}$ is the land area in transition from land scape $i$ to $j$.

\section{Land use dynamics}

To detect the change from 1 year to another, a comprehensive analysis method was applied in the present study. The comprehensive index model of land use grade is associated mainly with the principle that the natural complex of land is under the change of social factors (Jiyuan 1992). The model was classified into five categories depending on the degree of change from one period to another as shown Table 1 . The higher the degree of land use, the greater the degree of human interference and the worse the recoverability. From the index, the land use utilization index and land use degree classification index are used to evaluate the overall change characteristics of the land use category and then reflect the coupling association amongst the natural environment and human impact on the land use structure (Xiulan 2010; Jinpeng et al. 2010; Sisi et al. 2012).

$$
\begin{aligned}
& L=100 \times \sum_{i=1}^{n} A_{i} C_{I} \\
& \Delta L_{b-a}=L_{b}-L_{a}=100 \times\left[\sum_{i=1}^{n}\left(A \times C_{i b}\right)-\sum_{i=1}^{n}\left(A \times C_{i a}\right)\right] \\
& R=\frac{\Delta L_{b-a}}{\sum_{i=1}^{n}\left(A \times C_{i a}\right)}=100 \times \frac{\sum_{i=1}^{n}\left(A \times C_{i b}\right)-\sum_{i=1}^{n}\left(A \times C_{i a}\right)}{\sum_{i=1}^{n}\left(A \times C_{i a}\right)}
\end{aligned}
$$


Fig. 2 Flowchart showing the methodology of the present study

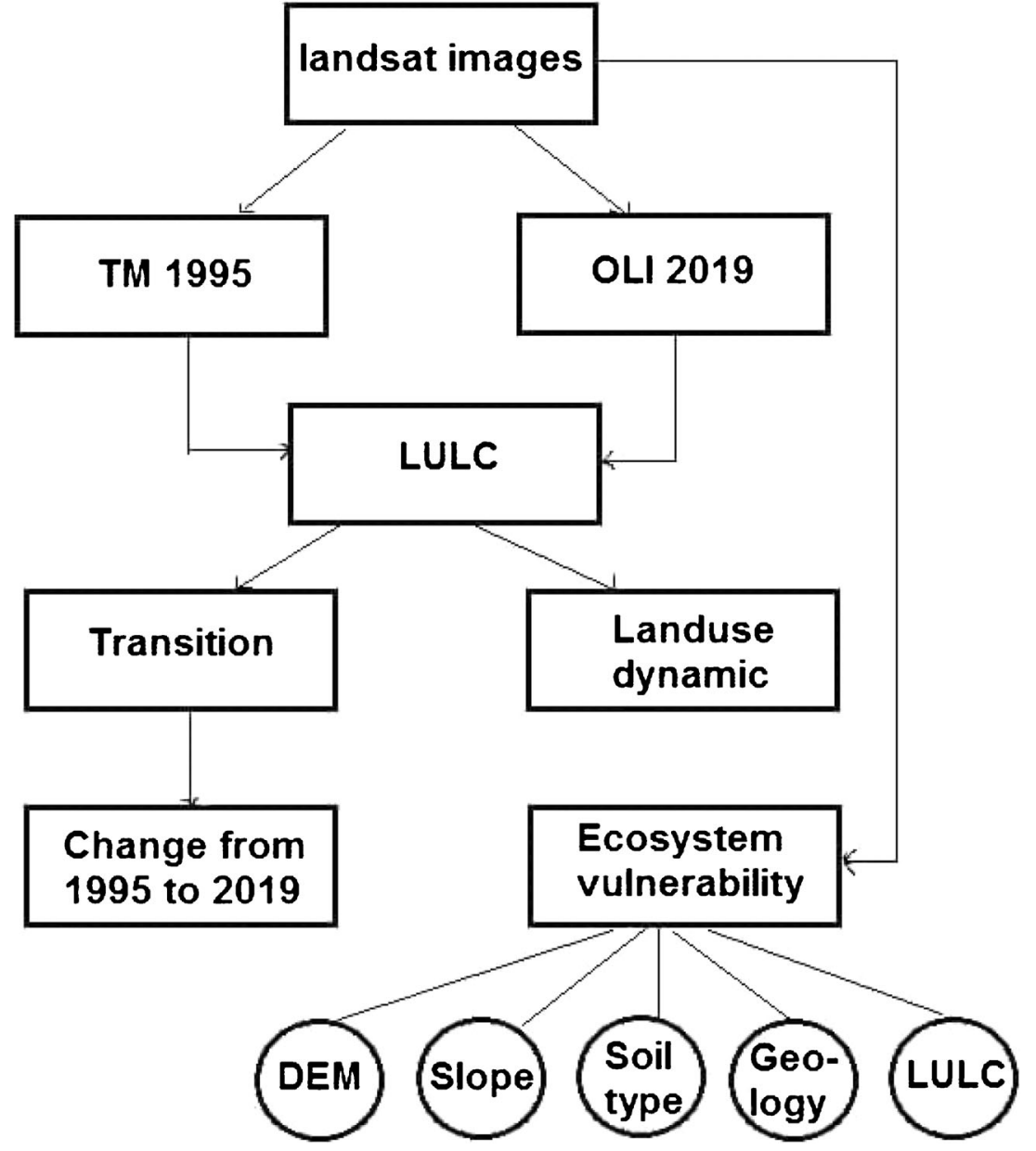

In the formula, $L$ represents the comprehensive index of land use degree, $L \quad 100-400$; the closer the $L$ is to 400 , the higher the degree of development and utilization; $A_{i}$ represents the classification index of land use type. $C_{i}$ represents the percentage of land use type area; $\Delta L_{b-a}$ represents the change in the comprehensive index of land use change; $L a$ and $L_{b}$ represent the comprehensive land use degree index of $a$ and $b$ time periods; $C_{i a}$ and $C i_{b}$ represent the area percentage of the i-type land type in the two periods $a$ and $b ; R$ represents the rate of change in land use. $R>0$ is the development stage; $R<$ 0 is the decay stage; $R=0$ is the stabilization or adjustment stage. According to the grading standards of land use degree

Table 1 Levels of comprehensive index degree

\begin{tabular}{lll}
\hline Intensity level & Land-use type & Value \\
\hline Unused level & Unused land and intertidal zone & 1 \\
Light utilization level & Water & 2 \\
Low utilization level & Grass, swamp and tidal & 3 \\
Strong utilization level & Irrigated land & 4 \\
High-strength utilization level & Construction land & 5 \\
\hline
\end{tabular}

index, the land use degree of construction land is the fourth level, including land for residents, mining, industry, transportation, etc.; the third level is farmland such as cultivated land; the second level is forest land, grassland, and water bodies. The first level is sand and other land types (El-Hamid et al. 2019).

\section{Ecosystem vulnerability}

The ecosystem of any area may be affected by natural and anthropogenic activities. To estimate the sensitivity of ecosystem, thematic maps of geology, DEM, soil, slope, and land use/cover were prepared from OLI image. The weight of every variable based on the weights of variables indicates the importance in relation to others (Tricart 1977). In natural susceptibility, all variables give similar weight; however, in ecological vulnerability, all variables were particular changed weight depending on their sensitivity or efficiency in the study area (Grigio et al. 2004). Ecosystem vulnerability includes natural and ecological. The degree of vulnerability for all units was from 0.0 to 3.0 (Table 2). The vulnerability was classified as extreme, 
Table 2 Weight of each variable in Ecosystem vulnerability

\begin{tabular}{|c|c|c|}
\hline Factor & Type/degree & Weight \\
\hline \multirow[t]{11}{*}{ LULC } & Bare land & 1 \\
\hline & Grass land & 1.5 \\
\hline & Industrial & 2.8 \\
\hline & Irrigated land & 1.3 \\
\hline & Swamp land & 1.4 \\
\hline & Tidal flat & 1 \\
\hline & Transportation & 1.7 \\
\hline & Urban land & 3 \\
\hline & Village land & 2.9 \\
\hline & Water bodies & 0.5 \\
\hline & Water channel & 0.5 \\
\hline \multirow[t]{5}{*}{ Slope $(\%)$} & $0-2.9$ & 0.5 \\
\hline & $2.9-8.2$ & 1 \\
\hline & $8.2-15.26$ & 2 \\
\hline & $15.26-25.24$ & 2.5 \\
\hline & $25.24-74.84$ & 3 \\
\hline \multirow[t]{5}{*}{ Elevation } & $1025-1205$ & 0.5 \\
\hline & $1205-1284$ & 1 \\
\hline & $1284-1410$ & 1.5 \\
\hline & $1410-1581$ & 2.5 \\
\hline & $1581-1775$ & 3 \\
\hline \multirow[t]{11}{*}{ Soil type } & Calcareous soil & 2 \\
\hline & Desert sandy soil & 2.3 \\
\hline & Calcareous stony soil & 1.8 \\
\hline & Residual solon chalk & 1.7 \\
\hline & Surface rust irrigation & 1.7 \\
\hline & Meadow saline soil & 1.4 \\
\hline & Alluvial soil & 2.5 \\
\hline & Salinized fluvo soil & 2.6 \\
\hline & Yellow river & 0.5 \\
\hline & Irrigated silt & 1.6 \\
\hline & New accumulated soil & 1.9 \\
\hline \multirow[t]{5}{*}{ Geology } & Alluvial deposit & 3 \\
\hline & Denudation low soil & 2.8 \\
\hline & Denudation high soil & 1.5 \\
\hline & Lime stone weathering & 2.6 \\
\hline & Yellow River & 0.5 \\
\hline
\end{tabular}

high, moderate, reasonable, and low vulnerability. The weights of variables show the importance of any variable in relation to others (Medjahed et al. 2016). Vulnerability was classified into five classes: low vulnerability that less than or equal to 1.00 , reasonable vulnerability that ranges 1.1 to 1.5 , moderate vulnerability that ranges from 1.51 to 2.00, high vulnerability which ranges from 2.1 to 2.50 , and extreme vulnerability that is more than or equal to 2.51 (Choudhary et al. 2018).
Vulnerability $=\frac{[\mathrm{DEM}]+[\text { Geology map }]+[\text { Soil map }]+[\text { LU } / \text { LC map }]+[\text { Slope }]}{5}$

\section{Spatial interpolation method}

The spatial interpolation model assessed here is calculated using ArcGIS10.5 software. Regression lines are helpful to know what interstitial values we could not practically know. It is useful to predict future values theoretically and can be trusted in statistical ways. Statistical models vary from simple linear to complexity nonlinear according to the nature of the phenomenon to be modeled. Models were proposed for prediction vegetation; water and bare lands of the study area are shown in equations. The accuracy and validation of statistical interpolation models depend on the coefficient of determination $\left(R^{2}\right)$. It is expressed by the ratio of total squares of regression divided by total squares. The value ranges between the correct one and zero and is calculated by the following equation.

$R^{2}=\frac{\left[\sum_{\mathrm{i}=1}^{\mathrm{n}}\left(O_{i}-\bar{O}\right)\left(f_{i}-\bar{f}\right)\right]^{2}}{\sum_{\mathrm{i}=1}^{\mathrm{n}}\left(\mathrm{O}_{\mathrm{i}}-\overline{\mathrm{O}}\right)^{2} \sum_{\mathrm{i}=1}^{\mathrm{n}}\left(f_{i}-\bar{f}\right)^{2}}$

where $n$ is he number of predicted value and $f_{i}$ denoted to our estimation of observed value $O_{i}$. And so, $\bar{O}$ and $\bar{f}$ are mean values of observed and estimation, respectively.

\section{Results and discussion}

\section{LULC in 1995 and 2019}

Based on supervised classification, eleven major land use classes were identified and mapped from both dates of satellite imageries to determine the changes and transformation (position and rate). These classes are village land, bare land, grass land, industrial land, irrigated land, swamp land, tidal flat, transportation land, urban land, water bodies, and water channels. These classes are demonstrated in Fig. 3. The majority area of the study areas are grassland. Grasslands are areas where the vegetation is dominated by grasses. Grassland varies in height from very short, as in chalk grassland, to quite tall. Annual changes in LULC were shown in Table 3. In the study area, grassland represents 65 and $59 \%$ of the study area in 1995 and 2019, respectively. It may be decreased with percentage $-5.873 \%$ due to some human practices and climate change from one season to another. Inventory of grassland to prohibit grazing is an effective measure for ecological recovery in the semi-arid desert steppe. Therefore, grassland, 

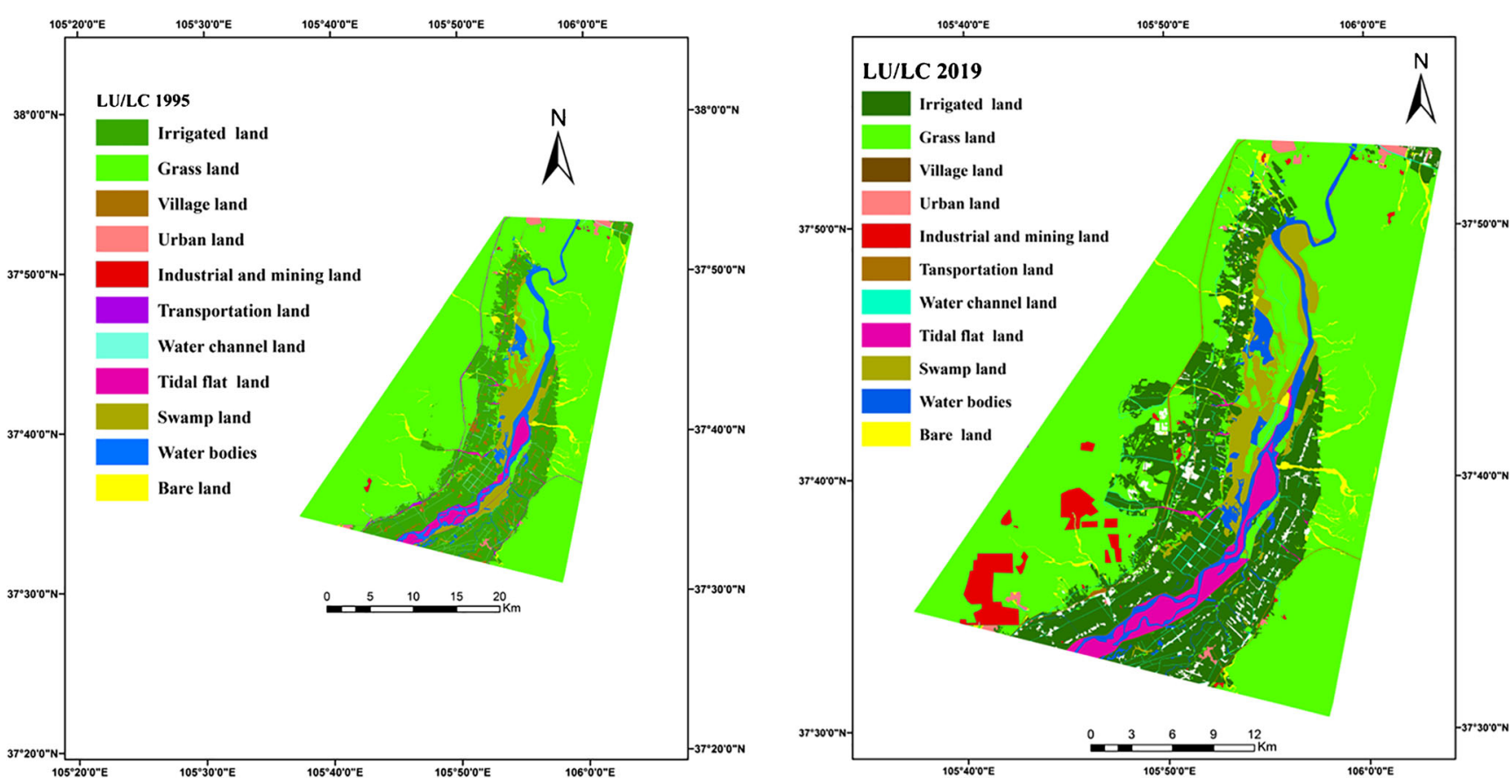

Fig. 3 Land use/cover map of land use in 1995 and 2019

construction of artificial grassland, scientific breeding, livestock improvement, prohibition, suspension, and rotation of grazing should be taken into consideration to improve the animal husbandry industry and help farmers and herdsmen to become rich. In this way, we can relieve that grassland can improve the ecological system's capability for selforganization and adjustment (Woodward et al. 2001). Urbanization may impact negatively on vegetation. Urbanization exerts intensive anthropogenic pressure on these areas. These places are highly modified and impacted by a large number of human activities (Mustafa et al. 2019). The industrial activities may be increased from 1995 to 2019 with percentage $2.595 \%$. Industrial practices have a negative influence in various ways, such as air emissions and accidental spills into the environment. Industry of the study area covers coal mining and coal industry product. Therefore, industry development promotes the growth and urban extension but at the same time brings about a degradation of land. The growth in urban regions originates from both the growth in migration to the cities and the fertility of urban populations. Much of urban migration is determined by rural populations' desire for the advantages that urban areas offer. Urban benefits include greater opportunities to receive education, health care, and services such as entertainment. The urban poor have fewer opportunities for education than the urban no poor, but still they have more chance than rural populations. Urbanization happens either organically or planned as a result of individual, cooperative, and government action. Living in a city can be culturally and economically helpful since it can deliver
Table 3 Quantitative evaluation of land use changes during the period from 1995 to 2019

\begin{tabular}{llllll}
\hline Class & Area & Area & $\begin{array}{l}\text { increase/ } \\
\text { decrease } \\
\left(\mathrm{km}^{2}\right)\end{array}$ & $\begin{array}{l}\text { Change } \\
(\%)\end{array}$ & $\begin{array}{l}\text { Yearly rate } \\
(\%)\end{array}$ \\
\hline Bare land & 13.92149 & 14.54816 & 0.626677 & 0.0667 & 0.00278221 \\
Grass land & 609.057 & 553.9372 & -55.1198 & -5.873 & -0.2447110 \\
Industrial & 1.108919 & 25.46738 & 24.35846 & 2.595 & 0.108142368 \\
Irrigated land & 184.3029 & 209.4387 & 25.13581 & 2.678 & 0.111593496 \\
Swamp land & 46.71449 & 40.89034 & -5.82415 & -0.62 & -0.02585703 \\
Tidal flat & 17.49095 & 26.1969 & 8.705954 & 0.927 & 0.038651145 \\
Transportation & 6.559587 & 5.882825 & -0.67676 & -0.072 & -0.0030045 \\
Urban land & 4.95691 & 5.791154 & 0.834244 & 0.088 & 0.003703729 \\
Village land & 11.61304 & 15.92496 & 4.311922 & 0.459 & 0.0191433 \\
Water bodies & 37.84963 & 33.47814 & -4.37149 & -0.465 & -0.0194077 \\
\hline
\end{tabular}


better probabilities for access to the labor market, better education, housing, and safety conditions, and reduce the time and expense of commuting and transportation. Land desertification stated by Zhu and Cui (1995) was not found in this study area, but land degradation in a total area of $55.62 \mathrm{~km}^{2}$, counting coal residue increase $(36.20 \%$ ), vegetation degradation, and soil salinity $(52.25 \%)$ was actually observed in Yinchuan, Shizuishan, and Pinglguo counties. The degradation rate was measured as $4.62 \mathrm{~km}^{2} /$ year. The irrigated land may be increased with percentage $2.67 \%$ from 1995 to 2019. The increase of these irrigated lands gives the chance for numerous crops to be cultivated in the area and raise the income of the district. Li and Zhou (2009) stated that the rapid expansion of built-up area in Ningxia is nevertheless undeniable for its very high growth rate (131.4\% in 11 years). The third is the rapid decrease of bare ground, which decreased $2652 \mathrm{~km}^{2}$ or $51.7 \%$. On the other hand, regular irrigation method should be followed to decrease the amount of water for cultivation. According to LULC, 22\% of the study area did not change from 1995 to 2019. It may be not exploited due to climate change. Fortyseven percent of the study area may be subjected to drilling processes.

\section{LUCC transition}

Major transition around the Yellow River from 1995 to 2019 was shown in Fig. 4. These transitions reflect the developmental activities in the study area.

\section{Gain transition of LUCC}

Among of LULC, seven classes were increased from 1995 to 2019; bare, industrial, irrigated, tidal flat, urban, village, and water channel as shown in Table 4. About $11.79 \mathrm{~km}^{2}$ of bare lands is reserved and will not be changed and $2.02 \mathrm{~km}^{2}$ of bare lands was converted to grass land. During the 24th year, small change was observed as a result of no exploitation of bare lands. For industrial lands, about $1.07 \mathrm{~km}^{2}$ is not changed and about $24.23 \mathrm{~km}^{2}$ was converted from grassland to industrial lands. Major transition of grasslands to industrial reflects the trend of population toward the industrial activities on account of grasslands. Due to the nature of the area, a large amount of area was converted to mining and industrial affecting negatively on vegetation and other types of LULC. About $180.47 \mathrm{~km}^{2}$ of irrigated lands is remaining constant and will not be changed but about $24.86 \mathrm{~km}^{2}$ of grassland was converted into irrigated lands. About $15.10 \mathrm{~km}^{2}$ of tidal flat is constant and $2.38 \mathrm{~km}^{2}$ was converted to water bodies. These new water bodies are used to reserve the agriculture area especially irrigated lands. For urban and village lands, $16.45 \mathrm{~km}^{2}$ is remaining constant; on the other hand, a low remarkable conversion has been occurred during the period of the study. All positive transition from 1995 to 2019 can affect negatively agriculture sector. Urbanization influencing vegetation is vital because this vegetation cover provides numerous critical ecosystem services and preserves a high level of biodiversity.

\section{Loss transition of LUCC}

Among of LULC, four classes were decreased from 1995 to 2019: grass, swamp, transportation, and water bodies as shown in Table 4. About $545.28 \mathrm{~km}^{2}$ of grassland is reserved and not changed and $2.11 \mathrm{~km}^{2}$ of grassland converted to bare lands. For swamp land, about $30.01 \mathrm{~km}^{2}$ is remaining constant and about $7.25 \mathrm{~km}^{2}$ was converted to grassland as shown in Fig. 4. About $27.53 \mathrm{~km}^{2}$ of water bodies is remaining constant and will not be changed but about 2.44 and $2.38 \mathrm{~km}^{2}$ of water bodies was converted to swamp and tidal flat, respectively. For transportation, about $5.87 \mathrm{~km}^{2}$ is remaining constant and no major transition occurred. The newly added traffic land is mainly transferred from grassland, and the newly added residential land is also transferred to the grassland, and the cultivated land also accounts for a certain proportion. Comprehensive consideration considers the area and proportion of ecological land use and believes that the ecological environment loss caused by the development and construction of industrial land and residential areas are relatively large. Spruce et al. (2020) stated that the more transitional LUCC classes were as expected particularly dynamic, including the shifting cultivation, scrub/shrub/herbaceous, and deciduous forest/scrub classes that can be related to cultivation practices. Among them, the area of damaged for forest land and industrial and construction is relatively large, and the development and construction of residential land have caused certain damage to cultivated land. Remarkable decrease in vegetation covers as a result of industrialization and climatic change of the study area. Land use dynamics may reflect the conversion of land use types as a result of recent changes (Mustafa et al. 2019).

\section{Land use dynamics}

Land use dynamic shows some developments of the area around the Yellow River from 1995 to 2019. The land use types of the area around the river were greatly changed from 1995 to 2019. As shown in Table 5, the comprehensive indices of land use in the two phases of 1995 and 2019 were 317.27 and 326.21, respectively: in the range of 100-400, indicating that land use has been in a reasonable development stage; the comprehensive land use index from 1995 to 2019 has continued to increase with a value 8.93 , and the degree of change in land use is greater than zero, indicating that the second phase is more developed and utilized. From the increase in the comprehensive index of land use degree, it is known that the construction has gradually entered a stable stage, and the land use pressure has gradually declined. 

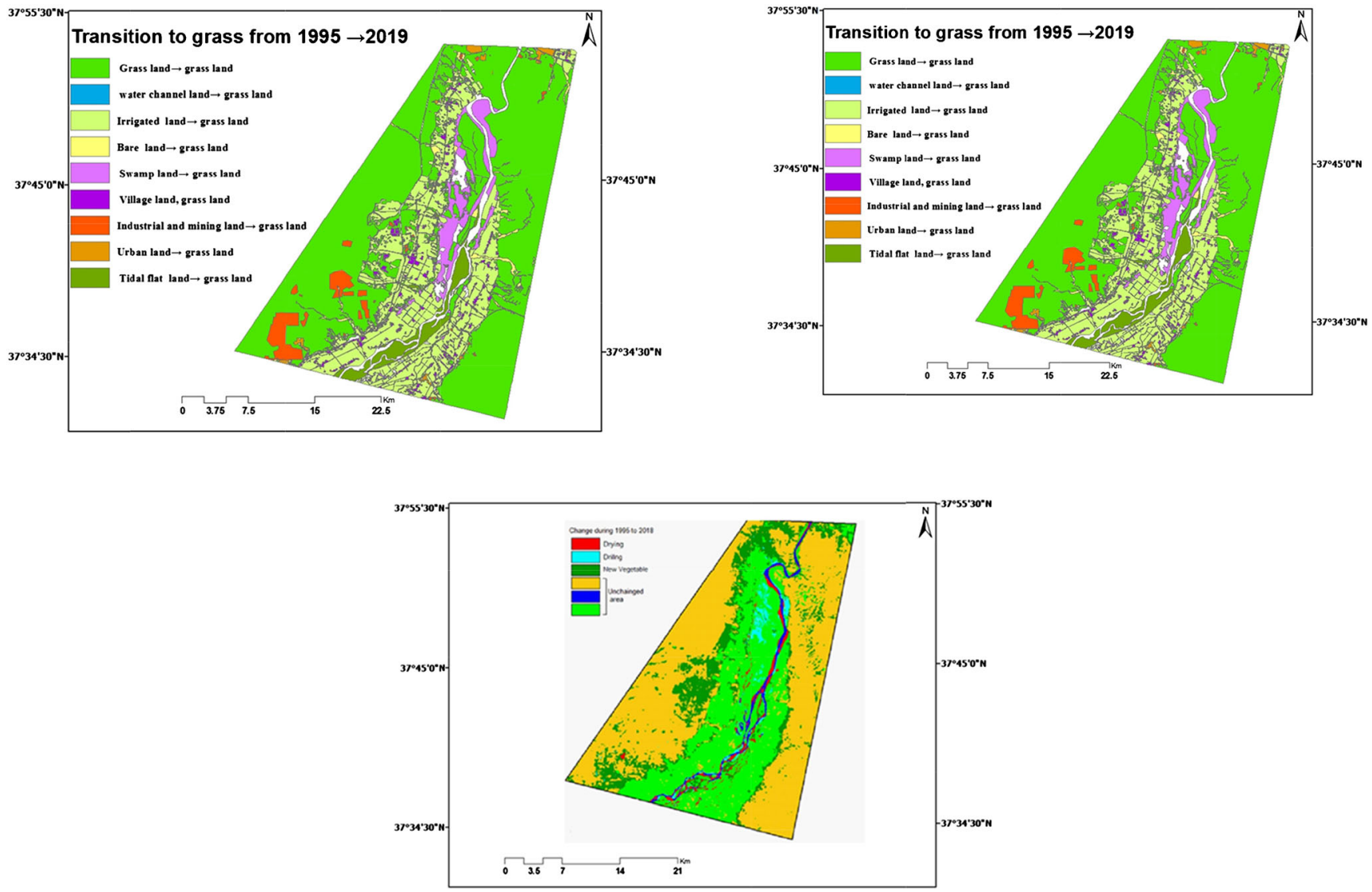

Fig. 4 Transition map of LU/LC, change of all classes to grass, and major changes from 1995 to 2019

\section{Ecosystem vulnerability}

Depending on some ecological factors, DEM, slope, LUCC, soil type, and geology of the study area, the ecosystem vulnerability index was calculated by the integration of some factors in the ecosystem as shown in Fig. 5. All factors were weighted according to the importance and according to previous study. DEM is a vital tool in determining the vulnerability of DEM and is responsible for extracting some factors associated with topographic conditions as slope and elevation. The

Table 4 Transition matrix of land use around the Yellow River

\begin{tabular}{|c|c|c|c|c|c|c|c|c|c|c|c|c|}
\hline & $\begin{array}{l}\text { Bare } \\
\text { land }\end{array}$ & Grass & Industrial & Irrigated & $\begin{array}{l}\text { Swamp } \\
\text { land }\end{array}$ & $\begin{array}{l}\text { Tidal } \\
\text { flat }\end{array}$ & Transportation & $\begin{array}{l}\text { Urban } \\
\text { land }\end{array}$ & $\begin{array}{l}\text { Village } \\
\text { land }\end{array}$ & $\begin{array}{l}\text { Water } \\
\text { bodies }\end{array}$ & $\begin{array}{l}\text { Water } \\
\text { channel }\end{array}$ & 2019 \\
\hline Bare land & 11.79 & 2.02 & - & 0.19 & 0.42 & - & 0.02 & 0.04 & - & 0.07 & 0.01 & 14.55 \\
\hline Grass & 2.11 & 545.28 & 0.04 & 0.97 & 4.47 & - & 0.22 & 0.01 & - & 0.82 & 0.02 & 553.94 \\
\hline Industrial & - & 24.23 & 1.07 & 0.13 & - & - & - & 0.03 & - & - & - & 25.47 \\
\hline Irrigated & 0.03 & 24.86 & - & 180.47 & 3.35 & 0.01 & 0.14 & 0.02 & 0.02 & 0.48 & 0.05 & 209.44 \\
\hline Swamp & - & 7.25 & - & 0.19 & 30.01 & - & - & - & - & 3.44 & 0.01 & 40.89 \\
\hline Tidal flat & - & 0.02 & - & 0.01 & 5.63 & 15.10 & 0.01 & - & - & 5.44 & - & 26.20 \\
\hline Transportation & - & - & - & 0.01 & - & - & 5.87 & - & - & - & - & 5.88 \\
\hline Urban land & - & 0.83 & - & 0.05 & - & - & 0.04 & 4.86 & - & - & - & 5.79 \\
\hline Village land & - & 2.18 & - & 1.90 & 0.01 & - & 0.23 & - & 11.59 & 0.01 & 0.01 & 15.92 \\
\hline Water bodies & - & 0.84 & - & 0.27 & 2.44 & 2.38 & 0.01 & - & - & 27.53 & 0.01 & 33.48 \\
\hline Water channel & - & 1.55 & - & 0.11 & 0.39 & - & 0.02 & - & - & 0.05 & 4.85 & 6.96 \\
\hline 1995 & 13.92 & 609.06 & 1.11 & 184.30 & 46.71 & 17.49 & 6.56 & 4.96 & 11.61 & 37.85 & 4.94 & 938.52 \\
\hline
\end{tabular}


Table 5 Change of land use dynamic from 1995 to 2019

sensitivity of ecosystem rises as the slope increases causing destruction to surrounding regions. Soil was classified into eleven class: calcareous soil, desert sandy soil, calcareous stony soil, residual solon chalk, surface rust, irrigation meadow saline soil, alluvial soil, salinized fluvo soil, Yellow river, new accumulated soil, and irrigated silt. Majority of the study area was classified as surface rust and irrigation soil. Soil plays a critical role in delivering ecosystem services. Managing to change an ecosystem development in sustenance of one modifiable ecosystem service can either provide co-benefits to other services or require trade-offs (Robinson et al. 2013). Geology of soil is classified as alluvial deposit, denudation low soil, denudation high soil, lime stone weathering, and Yellow River. Majority of soil geology is related to denudation low soil and lime stone weathering. Spatial analysis of ecosystem vulnerability index in 1995 shows that maximum area in safe and stable zone as $13.7 \%$ area in moderate vulnerability and $31.9 \%$ area in reasonable vulnerability zone, which shows that about $45 \%$ area of the total study area is safe zone. On the other hand, ecosystem vulnerability index in 2019 shows that maximum area in safe zone as $30.45 \%$ area in moderate vulnerability and $29.75 \%$ area in reasonable vulnerability zone, which shows that about $60 \%$ area of the total study area is safe zone. About $4.5 \%$ and $14.6 \%$ of areas goes in high vulnerability in 1995 and 2019, respectively, which really needs proper management. The low vulnerability area is $47.04 \% 19.05 \%$ for 1995 and 2019, respectively, which include the Yellow River and other water bodies in the study area. The extreme vulnerability area is $2.7 \%$ and $6.13 \%$ of the total study area in 1995 and 2019, respectively, which is close to water bodies as shown in Fig. 6. Annual rate of extreme and high vulnerability shows positive increase with a percentage $0.14 \%$ and $0.41 \%$, respectively, from 1995 to 2019 as shown in Table 6. Majority of vegetation area in zone under the moderate vulnerability zone; On the other hand, grasslands were subjected to high vulnerability. Low vulnerability and sensible vulnerability area are the safest area in the study area, which is under several amount of vegetation, urban, industrial, and bare lands. Vulnerability assessment is most easily associated with ecosystem like food production from agricultural land use, meat industry, fruit industry, fiber or timber production to forestry and cropland and energy production to the area used for bioenergy crops and oil and natural gas exploration, costal and manufacturing area. Climatic changes represent as a vital role in ecological vulnerability (Liu and Shi 2019). The services of ecosystem service really depends on biophysical growing conditions (Boori et al. 2015), in addition to increasing vegetation coverage, enhancing the capability for soil and water conservation, and strengthening controls on nonpoint contamination. However, strengthening environmental protection alone without improving socioeconomic and ecological unfamiliarity can only be a temporary degree. Therefore, it is essential to study the problems of socioeconomic and raise public environmental awareness as well as scientific understanding (Choudhary et al. 2018).

\section{Change and unchanged areas around the Yellow River}

According to the importance of Yellow River, drilling and drying were calculated as shown in Table 7. Drilling may be reflected in the reclamation and cultivation of some surrounding areas. Thirty-one percent of the study area may be also subjected to some drying. Drying processes are related to some human activities as industrial or other anthropogenic activities. As the Yellow River is almost the sole source of water resources for this region, the great impact of cropland expansion and urbanization has been recognized as one major cause that results in serious shortage of water resource in the lower reach of the Yellow River (Yang et al. 2004). Technical support for precision should be provided for employing precision agriculture and formulating poverty alleviation policies (Hong and Abd El-Hamid 2020).

\section{Statistical modeling of Yellow River changes}

The geostatistical techniques are the best spatial interpolation method to produce environmental change and also for the prediction standard error calculation. According to climatic change, some areas have been exposed to drying around the Yellow river as shown in Fig. 7. Results indicate that the model calculate $\left(R^{2}\right)$ was in the sequence $0.9334>0.8844>$ 0.6375 for vegetation, bare, and water, respectively. Where $(\mathrm{Y})$ is the prediction, $(\mathrm{X})$ is the year. The highest $R^{2}$, the most accurate method to predict the status of environmental changes in the study area, is shown in Fig. 6. Depending on random 

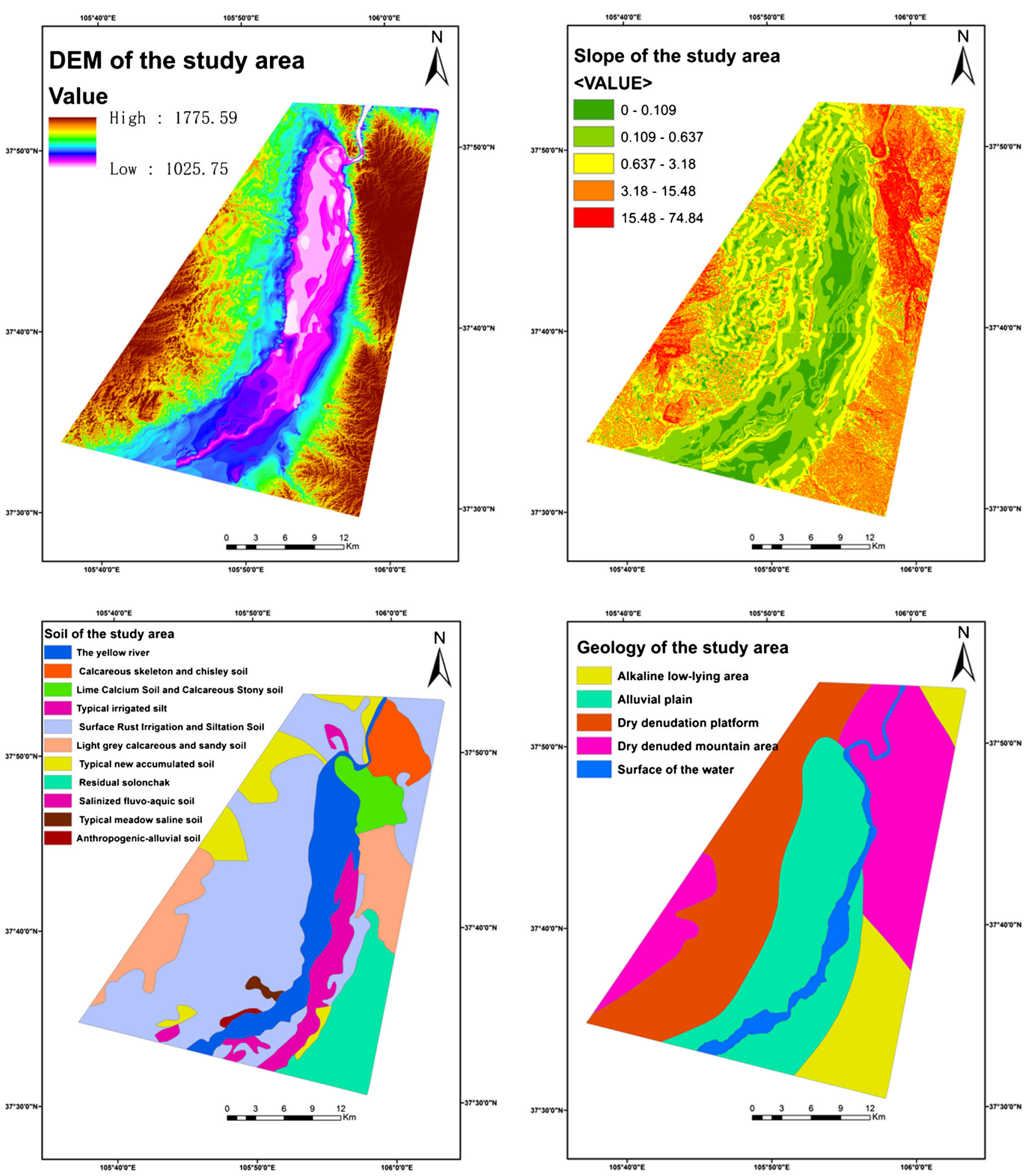

Fig. 5 Factors affecting on the ecosystem sensitivity

points in LULC, three equations were selected with high significant representing the change in water as flood, arid as drought, and vegetation. Red line represents the status of drought, from the model obvious increase in drought from 1 year to another. Through the high line under the known periods of drought, the lower the curve down is a period of scarcity of water in this year and between them and the high line above which decreases and the desert free space becomes a green reclaimed area year after year decline the curve of the desert and the agricultural land curve rises blue water, floods 

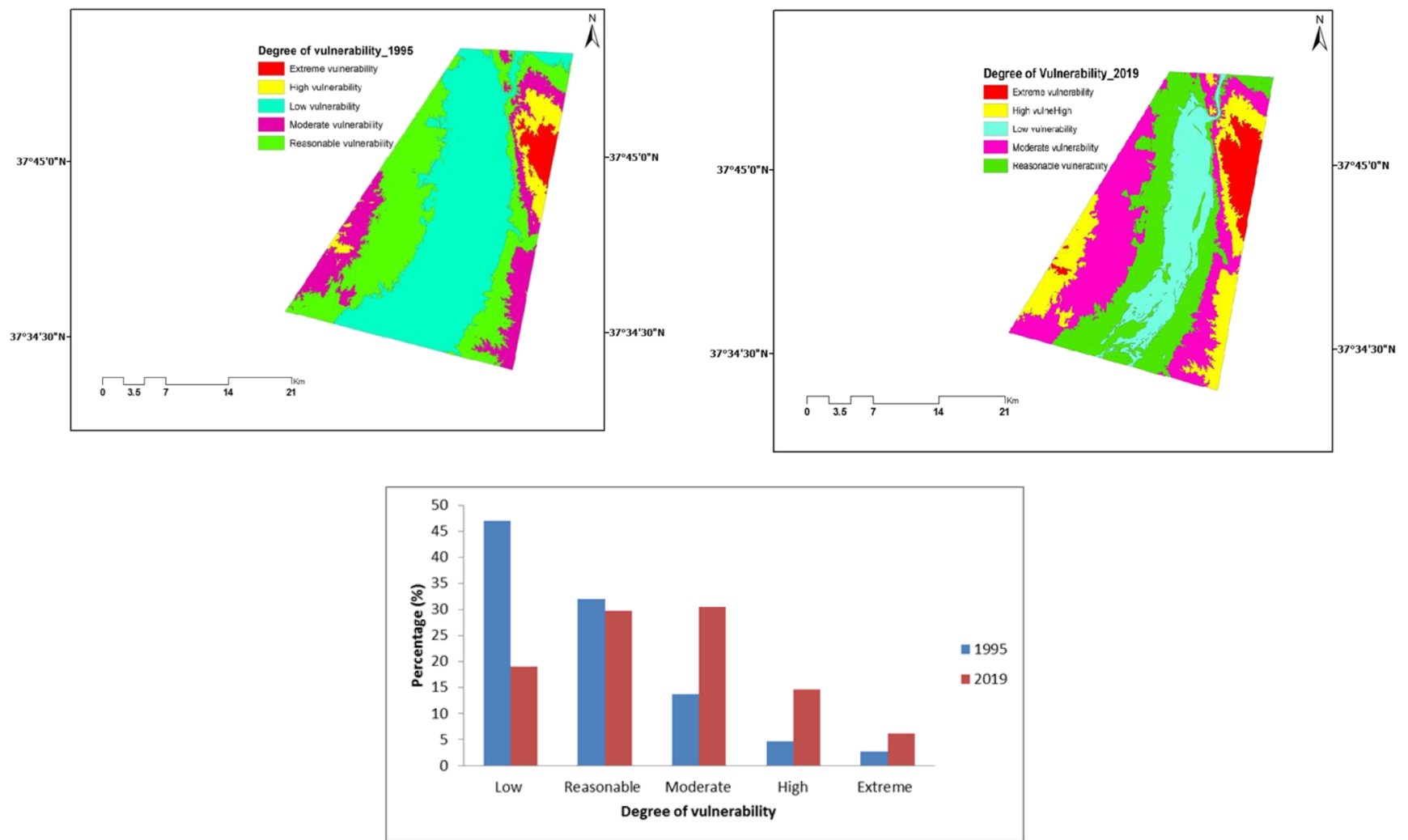

Fig. 6 Ecosystem Vulnerability Index ( $\left.E_{S} V I\right)$ percentage (\%) of ecosystem vulnerability index in 1995 and 2019
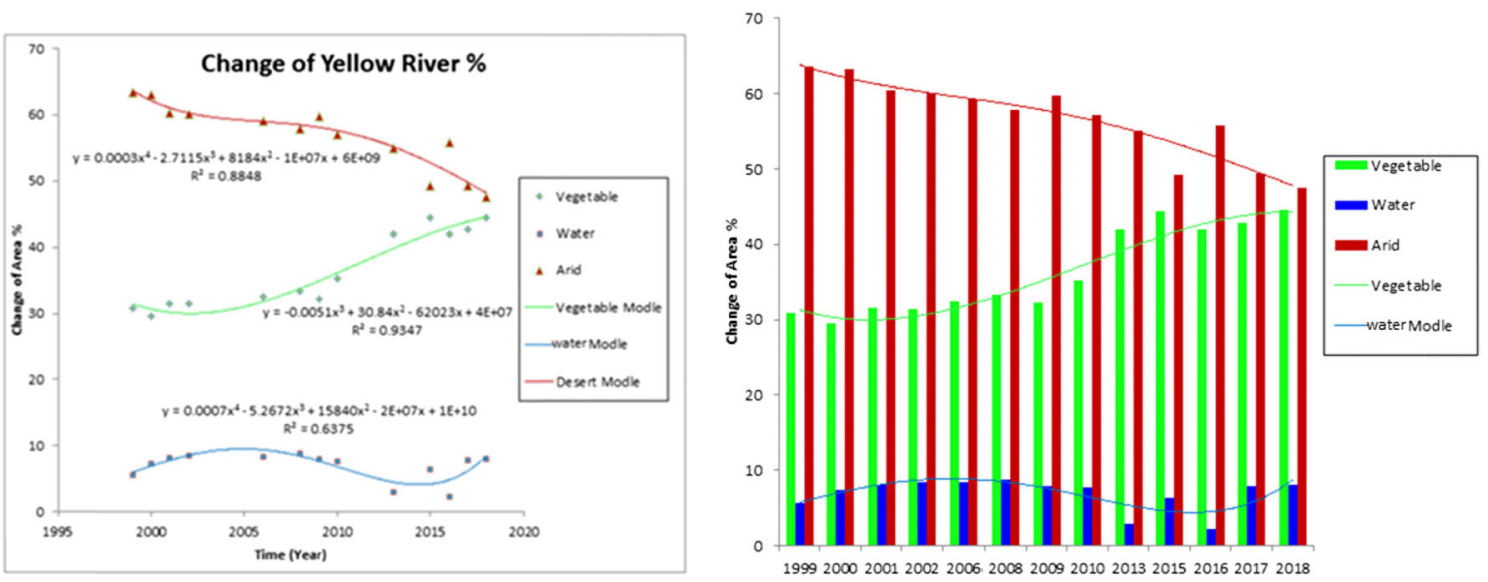

Fig. 7 Spatial mapping of change and unchanged during the period of the study area

Table 6 Area $\left(\mathrm{km}^{2}\right)$ with percentage of ecosystem vulnerability

\begin{tabular}{|c|c|c|c|c|c|}
\hline \multirow[t]{2}{*}{ Class } & \multicolumn{2}{|c|}{ Area $\left(\mathrm{km}^{2}\right)$} & \multicolumn{2}{|c|}{ Percentage $(\%)$} & \multirow[t]{2}{*}{ Annual rate $(\%)$} \\
\hline & 1995 & 2019 & 1995 & 2019 & \\
\hline Low vulnerability & 411.65 & 166.787319 & 47.04034 & 19.05888 & -1.16588 \\
\hline Reasonable vulnerability & 279.561 & 260.352304 & 31.94618 & 29.7506 & -0.09146 \\
\hline Moderate vulnerability & 119.971 & 266.51116 & 13.7094 & 30.45438 & 0.697731 \\
\hline High vulnerability & 40.128 & 127.813851 & 4.585533 & 14.60536 & 0.417504 \\
\hline Extreme vulnerability & 23.79 & 53.651422 & 2.718546 & 6.130776 & 0.142181 \\
\hline \multicolumn{5}{|c|}{ Total annual rate of ecosystem vulnerability from 1995 to 2019} & -4.16667 \\
\hline
\end{tabular}


Table 7 Drilling and drying according to major change in water

\begin{tabular}{lll}
\hline Process & 1995 & 2019 \\
\hline No change & 1167300 & 2.06 \\
Drilling & 2554770 & 4.52 \\
Drying & 1708875 & 3.02 \\
\hline
\end{tabular}

and floods if the decline remains in drought because the desert land turns to agriculture.

\section{Conclusions}

Assessment of ecosystem vulnerability considers a vital factor for qualifying and achieving ecosystem stability. This study examined the effect of LULC and climatic change on the ecosystem in North Ningxia using ecosystem sensitivity index $\left(E_{S} V\right)$ for the period 1995 to 2019 . It is clearly that the study area is subjected to major changes in LUCC from 1995 to 2019. These changes may be related to natural and anthropogenic activities. Climatic change is the main factor that controlling the change in ecosystem of the study area. Grassland occupies the largest area in 1995 and 2019, but it represents 65 and $59 \%$ of the study area in 1995 and 2019, respectively. About $24.23 \mathrm{~km}^{2}$ and $24.86 \mathrm{~km}^{2}$ was transformed from grassland to industrial lands and irrigated lands, respectively. The results indicated a large presence of area with moderate vulnerability 45\% and 60\% for 1995 and 2019, respectively. The annual rate of $E_{S} V I$ decreased in low and reasonable but it was increased in moderate, high, and extreme showing $-4.166 \%$ as a total percentage of annual vulnerability. High and extreme vulnerability show positive rate from 1995 to 2019 as a result of anthropogenic activities and urbanization. Therefore, the current study showed a model of ecosystem vulnerability that can be used as an important indicator for engineers, governmental institutions, and researchers. It is recommended to apply this model in the zone with the similar properties of climate.

Open Access This article is licensed under a Creative Commons Attribution 4.0 International License, which permits use, sharing, adaptation, distribution and reproduction in any medium or format, as long as you give appropriate credit to the original author(s) and the source, provide a link to the Creative Commons licence, and indicate if changes were made. The images or other third party material in this article are included in the article's Creative Commons licence, unless indicated otherwise in a credit line to the material. If material is not included in the article's Creative Commons licence and your intended use is not permitted by statutory regulation or exceeds the permitted use, you will need to obtain permission directly from the copyright holder. To view a copy of this licence, visit http://creativecommons.org/licenses/by/4.0/.

\section{References}

Abd El-Hamid HT, Wenlong W, Qiaomin L (2019) Environmental sensitivity of flash flood hazard using geospatial techniques. Glob J Environ Sci Manag 6(1):31-46. https://doi.org/10.22034/gjesm. 2020.01.03

Aldwaik SZ, Pontius RG (2012) Intensity analysis to unify measurements of size and stationary of land changes by interval, category, and transition. Landsc Urban Plan 106:103-114. https://doi.org/10. 1016/j.landurbplan.2012.02.010

Azpurua M, Ramos KD (2010) A comparison of spatial interpolation methods for estimation of average electromagnetic field magnitude. Prog Electromagn Res 14:135-145. https://doi.org/10.2528/ PIERM10083103

Boori MS, Vozenilek V, Choudhary K (2015) Land use/cover disturbances due to tourism in Jeseniky Mountain, Czech Republic: a remote sensing and GIS based approach. Egypt J Remote Sens Space Sci 18(1):17-26. https://doi.org/10.1016/j.ejrs.2014.12.002 ISSN 1110-9823

Choudhary K, Boori MS, Kupriyanov A (2018) Spatial modelling for natural and environmental vulnerability through remote sensing and GIS in Astrakhan, Russia. Egypt J Remote Sens Space Sci 21: 139-147. https://doi.org/10.1016/j.ejrs.2017.05.003

Choudhury D, Kalikinkar D, Arijit D (2019) Assessment of land use land cover changes and its impact on variations of land surface temperature in Asansol-Durgapur Development Region. Egypt J Remote Sens Space Sci 22(2):203-218. https://doi.org/10.1016/j.ejrs.2018. 05.004

El-Hamid HTA, Caiyong W, Yongting Z (2019) Geospatial analysis of land use driving force in coal mining area: case study in Ningdong, China. GeoJournal. https://doi.org/10.1007/s10708-019-10078-2

Grigio AM, Castro AFD, Souto MVS, Amaro VE, Vital H, Diodato MA (2004) Use of remote sensing and geographical information system in the determination of the natural and environmental vulnerability of the Guamaré municipal district - Rio Grande do Norte - northeast of Brazil. J Coastal Res SI 39, pg. Itajaí, SC - Brazil, ISSN 07490208.https://www.academia.edu/27741486

Hong G, Abd El-Hamid HT (2020) Hyperspectral imaging using multivariate analysis for simulation and prediction of agricultural crops in Ningxia, China. Comput Electron Agric J 172:105355. https://doi. org/10.1016/j.compag.2020.105355

Jinpeng L, Fei W, Xingmin M (2010) Effects of land use change on the value of ecological services in Yanhe River Basin. Soil Water Conserv Res 17(3):110-114

Jiyuan L (1992) Land use in Tibet Autonomous Region. Science Press, Beijing, pp 1-60

Kandissounon GA, Kalra A, Ahmad S (2018) Integrating system dynamics and remote sensing to estimate future water usage and average surface runoff in Lagos, Nigeria. Available online at www. CivileJournal.org. Civ Eng J 4(2). https://doi.org/10.28991/cej030998

Li X, Liu X (2008) Embedding sustainable development strategies in agent-based models for use as a planning tool. Int J Geogr Inf Sci $22: 21-45$

Li B, Zhou Q (2009) Spatial pattern of land cover change in China's semiarid environment. J Arid Land 1(1):16-25

Liu Q, Shi T (2019) Spatiotemporal differentiation and the factors of ecological vulnerability in the Toutun River basin based on remote sensing data. Sustainability 11:4160. https://doi.org/10.3390/ su11154160

Medjahed SA, Saadim TA, Benyettou A, Ouali M (2016) A new postclassification and band selection frameworks for hyperspectral image classification. Egypt J Remote Sens Space Sci 19:163-173. ISSN 1110-9823. https://doi.org/10.1016/j.ejrs.2016.09.003 
Mustafa EK, Liu G, Abd El-Hamid HT, Kaloop MR (2019) Simulation of land use dynamics and impact on land surface temperature using satellite data. GeoJournal. https://doi.org/10.1007/s10708-01910115-0

Ozesmi SL, Bauer ME (2002) Satellite remote sensing of wetlands. Ecol Manag 10(5):381-402

Rahman A, Parvin GA, Shaw R, Surjan A (2016) Cities, vulnerability, and climate change. In: Shaw R, Rahman A, Surjan A, Parvin GA (eds) Urban Disasters and Resilience in Asia, 1st edn, pp 35-47. https://doi.org/10.1016/B978-0-12-802169-9.00003-3

Robinson DA, Hockley N, Cooper DM, Emmett BA, Keith AM, Lebron I, Reynolds B, Tipping E, Tye AM, Watts CW, Whalley WR, Black HIJ, Warren GP, Robinson JS (2013) Natural capital and ecosystem services, developing an appropriate soils framework as a basis for valuation. Soil Biol Biochem 57:1023-1033. https://doi.org/10. 1016/j.soilbio.2012.09.008

Saaty TL, Vargas LG (1991) Prediction, projection and forecasting, research on eco-environmental vulnerability evaluation of the Anning river basin in the upper reaches of the Yangtze River. Environ Earth Sci 72(5):1555-1568

Sisi X, Chunxi W, Jinyu C (2012) Analysis of land use change and driving factors in Taihu Lake Region: 1980 to 2005. J Agricl Eng 28(23): $1-2$
Spruce J, Bolte J, Mohammed IN, Srinivasan R, Lakshmi V (2020) Mapping land use land cover change in the Lower Mekong Basin from 1997 to 2010. Front Environ Sci 8. https://doi.org/10.3389/ fenvs.2020.00021

Tricart E (1977) Revista Brasileira de Geomorfologia Ano 8, no 2 (2007)

Vaidya P, Satish KB, Sahil S (2018) Land use and land cover changes in Kullu valley of Himachal Pradesh. Indian J Agric Sci 88(6):902906

Woodward FI, Lomas MR, Lee SE (2001) Predicting the future productivity and distribution of global terrestrial vegetation. In: Roy J, Saugier B, Mooney HA (eds) Terrestrial global productivity. Academic, San Diego, pp 521-541

Xiulan W (2010) Analysis of population factors in land use/land cover change. Resour Sci 22(3):39-42

Yang D, Li C, Hu H, Lei Z, Yang S, Ta K, Koike T, Musiake K (2004) Analysis of water resources variability in the Yellow River of China during the last half century using historical data. Water Resour Res 40(6):W06502. https://doi.org/10.1029/2003WR002763

Zhu ZD, Cui SH (1995) Desertification in China: status, trends and strategies. J Chin Geogr 5:32-42 